\title{
MOTIVATION OF STAFF IN HEALTHCARE ORGANIZATIONS
}

\author{
T. Stoev ${ }^{1 *}$, K. Kanalev ${ }^{2}$ \\ ${ }^{1}$ Faculty of Public Health and Health Management, Medical University - Plovdiv, Bulgaria \\ ${ }^{2}$ Faculty of Medicine, Medical University - Plovdiv, Bulgaria
}

\begin{abstract}
The mission of healthcare in the 21 st century is to improve quality of life in global, regional, national and individual dimensions, which is why health and healthcare are a national priority and a primary state and public task. In order to achieve this mission, it is necessary, among other things, to provide the necessary human resources for the delivery of health services, as well as its effective management, part of which is motivation.

The problem of motivation of behaviour in labour is one of the central objects in the functioning of each organization. The establishment and operation of an organization, and the health organization, requires the development of adequate tools and mechanisms for integrating, regulating and directing individual participation in solving common tasks and problems. In this regard, the central goal of the organization's leadership is, figuratively speaking, to "harness" the individual needs and opportunities in the joint venture. One of the ways to achieve this goal is knowledge and impact on the motivation of staff.
\end{abstract}

Key words: motivation, staff, health institutions.

The mission of healthcare in the 21st century is to improve quality of life in global, regional, national and individual dimensions, which is why health and healthcare are a national priority and a primary state and public task. In order to achieve this mission, it is necessary, among other things, to provide the necessary human resources for the delivery of health services, as well as its effective management, part of which is motivation.

The problem of motivation of behaviour in labour is one of the central objects in the functioning of each organization. The establishment and operation of an organization, and the health organization, requires the development of adequate tools and mechanisms for integrating, regulating and directing individual participation in solving common tasks and problems. In this regard, the central goal of the organization's leadership is, figuratively speaking, to "harness" the individual needs and opportunities in the joint venture. One of the ways to achieve this goal is

*Correspondence to: Todor Stoev, Faculty of Public health and health management, Medical University - Plovdiv, Bulgaria, 15A Vasil Aprilov Blvd., Plovdiv, 4002, 0889697006, e-mail: todor_stoev@abv.bg knowledge and impact on the motivation of staff (1).

Motivation of human resources is part of the subject of management. It involves knowing and managing the mechanisms of individual and group motivation. The problems of motivation of human behaviour in labour and labour are becoming essential for the successful functioning of organizations in market conditions. The focus on motivational issues is constantly increasing, and the need for managing it at all hierarchical levels is growing. Over the past thirty years, it has been one of the most discussed topics in management.

Management is both science and art. To manage effectively, managers need to possess not only the necessary skills to manage but also a number of other skills acquired over time, experience and practice (2). On the other hand, the management also includes aspects of scientific orientation. To work at a high level, managers need to be able to use science - in particular medicine, economics, psychology, sociology, political science, mathematics, anthropology and others, because the key to successful governance is the systematic study 
of why and how people work together to achieve certain goals.

Effective management of human resources is based on the use of modern methods, tools and tools from the world and Bulgarian practices in this field and requires leaders who have high morals, values and behavioural models that meet the stated values of the organization, who understand the significant effect of improving governance and who are working to improve the human resources system to achieve better results.

The mission of human resource management in the health organization is to identify, develop and maintain the most suitable people to work for the benefit of public interest and to enhance the organization's prestige. The vision is for modern, competent, transparent and effective human resources management that creates capable, responsible and motivated employees with the necessary competencies and potential for successful implementation of the management objectives.

There are many features that need to be understood and studied to understand the nature of motivation and the motivation process itself. The term "motivation" derives from the Latin word "movere", meaning "move", respectively "motivation" - "drive", "movement".

Psychologists understand the word "motivation" as the influence of a set of internal and external forces on the individual, as a result of which one realizes a certain behaviour, determines the form, the intensity, the duration and the direction of his actions to achieve certain goals. Research on motivation deals with such issues as: "why people choose a particular mode of action for others and continue to act in the chosen way for long periods, even when faced with certain difficulties and obstacles." There is a long way to go to search for answers to this question. One answer is - our food, security, protection, belonging, recognition, and at the same time the sense of growth and achievement are the main drivers of our behaviour (3).

Motivation is a process of making a voluntary decision for a certain purposeful act or omission in the presence of a certain situation. It is subjective in the individual's consciousness and is limited to personal appreciation of all the actions on it, of the signals given to it by the economic, organizational and social environment of the organization.
STOEV T., et al. Understood in this way, motivation precedes and predetermines the behaviour of employees in the work process, their activity and the degree to which they attribute their intellectual and physical abilities. Naturally, the manager would like the staff to have such behaviour in the work process, which would produce the best possible results. In order to achieve this, he has to select and send such signals to the employees who would motivate them for highperformance work. This activity of managers characterizes the process of motivation, ie. creating such an economic, organizational, and social environment within an enterprise or organization to make employees choose the behaviour in the work process that is in line with the strategy developed. To motivate is to make people move in the direction you want. Also, take the necessary steps to get there. Being motivated means either wanting to go somewhere at your own will, or being encouraged with all the resources available to go about purposefully and to make a success on your arrival.

Here we have to make a distinction that motivation is an objective process, and motivation is a managerial impact on motivation. Motivation, as a mental process, and motivation, as a manager's activity, is directly related to the general economic, social and political environment in the country during the given period.

Motivation plays an important role and plays an important role in the functioning of modern organizations, including health organizations. The appearance of the individual in the organization is a function of the work by its abilities and its motivation:

Presentation $=\mathrm{f}$ (capabilities) $\mathrm{x}$ (motivation)

On the other hand, abilities are a function of the work of education, experience and learning:

Abilities $=\mathrm{f}$ (education) $\mathrm{x}$ (experience) $\mathrm{x}$ (training)

Changes in education, experience and training require a prolonged period of time and considerable material resources, so motivation allows a more rapid effect to be achieved (4).

Motivation is a process of stimulating an individual or group of people to pursue an activity aimed at achieving the organization's goals. It has two forms that influence the person to behave in a certain way or to move in a certain direction (5). To motivate is to be able to get people to move in a direction that the manager has defined. But what the manager wishes does not always match with the desire of the people, so one of the reasons Trakia Journal of Sciences, Vol. 16, Suppl. 1, 2018 
for motivation is for the members of the organization to be fully satisfied.

Motivation is the key issue for managing human resources in the organization. Managers are interested in working motivation in the following aspects:

$\checkmark$ Motivation for work at all.

$\checkmark$ Motivation for specific activity (position).

$\checkmark$ Motivation for work in a particular organization (loyalty).

$\checkmark$ Motivation to achieve the best results (engagement).

Effective managerial impact on work motivation needs constant, adequate and sufficient "site information" - workers and employees. This is done by developing the socalled motivation profiles for determining the motivational impact on the employees of the organization.

At the heart of every motivation is the hope for example, the hopeful that if we work well, we will live well. In this sense, money as a fruitful result of our work should also be seen as a motivator. In fact, they are only a supportive factor. The saying "happiness with money is not being bought" is known, but the Georgians say, "God, give us health, the other with money will buy it." The truth, as always, is somewhere in the middle.

\section{REFERENCES}

1. Borisov, V. Health Reform - Myth or Reality. Health Management, issue 3, 2008

2. Borisov, V. Health Management, vol. 1, Alphabet of Health Management, Sofia 2005

3. Borisov C. Strategic Management - Deficit of Health Reform. Health Management 5, 2005, 6

4. Borisov, V. Health Management with Fundamentals of Health Policy, Sofia, 2003.

5. Borisov, V., T. Vodenicharov. Realities of Health Reform. S., 2000 